\title{
An Empirical Assessment of the Relationship between Inflation and Investment in Nigeria
}

\author{
Olufunke Bosede Olufemi, Adeleke Omolade and Obasuyi, F.O.T \\ Department of Economics, College of Education, Ikere-Ekiti, Nigeria
}

\begin{abstract}
This study examined empirically the impact of inflationary rate on the level of investment in a developing economy a case study of Nigerian Economy 1970-2008. The study adopted co-integration and error correction model as the estimating techniques. The empirical results showed that there is a long run relationship between inflationary rate and investment in Nigeria. Unlike some developed nations where inflation has direct relationship with the investment, in Nigeria, low rate of inflation and increased national income would promote investment. The policy recommendation is that Nigeria government should strive to curtail inflation to the minimum while accelerating the growth of the national income in her quest to boost investment.

Key Words: Inflation Rate, Investment, Developing Economy.
\end{abstract}

\section{Introduction}

Generally, inflation symbolizes a situation of rapid persistent and unacceptable high rise in the general price level in an economy resulting in the loss of purchasing power of the country's currency. The high rate of inflation, which Nigeria has been experiencing since the 1970s has its origin in the economic measure and control that were enacted during the Nigeria civil war of 1967-1970. Prior to the war, Nigeria practiced the open market economic policy with very little government control. Investment on the other hand is known to constitute the main engine of growth in any economy. Infact, Odoko (2003) describes it as the major catalyst for economic development. Investment is financed from savings (domestic or foreign), but as a result of insufficient domestic savings in the developing economy like Nigeria due to low income and inefficient financial system, foreign saving is required to supplement domestic savings in finace of investment. Osakwe (1982) points out that inflation reduces the volume of savings and the more persistent and stronger the inflation, the lower is the level of saving and investment. There are basically three major approaches used in measuring inflation the deflation of the gross national product (GNP), which implicitly measures inflation, the consumers' price index (CPI) and the wholesale price index (WPI). In Nigeria the most widely used measure of inflation is the consumer price index because it is readily available on monthly, quarterly and annual basis.

In the classicalist theory of monetary transmission mechanism, increased money stock only leads to an inflationary pressure on the economy thereby leaving the real sector where investment belongs unaffected. According to Rostow, (1934) inflation has been important for several industrial take off. But then, there is a level of inflation that can be considered conducive for economic growth. i.e that will promote growth through increase in investment. The problem therefore lies in determining the inflation rate consistent with development and identifying the price that reflect a conducive inflationary pressure on the economy.

It is therefore imperative that there have been some arguments surrounding the relationship between inflationary rate and economic development. While the classical economist believe that inflationary rate doesn't affect the real sector where investment belong, economist like Rostow is of the opininon that inflation plays a majpor role in industrial take off i.e it has the tendency of promoting capital accumulation.

\section{Literature Review and Theoretical Framework}

There have been several studies on inflation related ioissues in different journal and publications both local and international. For instance, Bhatia (1960) and Eckstein (1958) attempted to review that Rostow's thesis did not completely show that the take off stages of economic development has typically been associated with inflation. Looking at the historical relation between inflation and economic growth in five countries, Bhatia find no evidence that take off in Sweden, Japan and Canada was assocaietd with inflation He concluded that relation between inflation and growth has been on the increase in the United Kingdom, Germany and Japan and significantly positive only in Sweden. Eckstein (1958), carrying out a test on the effect of inflation on economic growth for eight industrialized countries. He concluded that period of rapid economic growth occurred without inflation showing that there is no historical relationship between inflation and economic growth, but this he said it occurred up to a critical rate of inflation after it will decline. Thirallich (1974) in a cross-section study of forty-three countries over the period of (1956-1965) finds inflation to be negatively related with growth. His study concludes that depressing effect of inflation on economic growth works through the worsening of the economic distribution and the cost of investment. Also, in a study conducted by Durance (1975) in the 
relationship between inflation, growth and the level of per capital income was examined. He suggested that in asituation where growth rise with the rate of inflation up to a point and then begins to decline and in a situation where growth rise with level of per capital income and then declines we should expect the evidence to conform to a mild inflation as growth rises. However, the relationship between investment and inflation has been seen by various economists using different economies in diverse perspectives. While some see it to be positive some see it to be negative. This study therefore attempts to study the relationship by focusing on the impact of inflationary rate on investment using Nigeria Economy as case study.

\section{Theoretical Framework}

\section{Demand and pure Cost Push Theories}

The demand-pull theory ascribe rising prices to excess demand. In the goods market, prices rise because the claiming on a society's resources from investors and consumers in money when terms exceed the economy's real productive potential. Thus, this type of inflation occurs when aggregate demand rises faster than aggregated suplly. In the arely 1960s, Nigeria experienced a mild inflation or single digit inflation, which is said to be consistent with the process of economic growth. It would therefore be unrealistic to ascribe the inflation during the early stages of development in Nigeria to demand pull forces. The pure cost model of inflationary process indicated that inflation arise from increases in the cost of production, especially rising wage emanating from trade union actions. According to Iyoha (1975), Inflation in Nigeria can be attributed to both demand and supply phenomena as well as the openness of the Nigerian economy and just one related factor.

\section{The Monetarist Theory of Inflation}

From the monetarist perspective, inflation is always and everywhere a monetary phenomenon and maintains a policy of monetary and physical stability is a basic prerequisite for rapid economic development. The monetarist theory of inflation is linked with Friedman and Schwartz. Accordingly, they believe that inflation is a monetary phenomenon and as such can only be viewed in terms of increase in the stock of money in the economy.

Monetarist see the arrow of causation in the equation of exchange (MV=PY) as going from left of prices. This direct cavsation was supported by the empirical work of Micron Friedman (1968) and Schwartz (1973) Schwartz like Friedman carried out his empirical study by means of simple data contumely forth countries covering the period (1959-1969). The result showed a high positive correlation between money supply and prices which is consultant with a Friedman (1968) statement that the level of the rate of growth of money supplies whether domestic or global determines the prices level. The monetarist therefore view money supply as exogenously determined and such can be controlled only by the monetary authorities.

\section{The Classical Theory of Investment}

The classical theory state that planned investment will equal planned savings and the equilibrating factor is the interest rate. They argued that $\mathrm{S}=\mathrm{f}(\mathrm{r}), \mathrm{F}^{1}(\mathrm{r})<0, \mathrm{i}=\mathrm{f}(\mathrm{r}), \mathrm{f}^{1}(\mathrm{r})<0$.

Thus, in the classical theory, interest rate as a very powerful factor, which influence investment. Thus, investment is interest elastic.

\section{The Keynesian Theory of Investment}

Keynesian attacked the classical theory for the exclusion of income as a fundamental determinant of savings. The classicalists said that interest can adjust intermittently towards equilibrium but the Keynesians said this is not realistic that there will be monetary and fiscal policies to decide what the rate of interest will be. In the Keynesian model. $I=i(r)$, owever, since at equilibrium, saving equals investment, we have $S=I,(y)=I(y, r)$, $(\mathrm{y})>0,(\mathrm{r})<0$

\section{The Accelerator Principle}

The accelerator principles take two different forms. The simple accelerator principle and the flexible accelerator otherwise called the capital stock adjustment principles.

J.N. Clarke (1963) in business accelerator and the law of demand developed simple accelerator. The theory states that the rate of investment expenditure depends on upon changes in the levels of output. That is increase in output puts pressure on existing production capacity, which necessitates an expansion of the capital stock and in turn necessitates a higher rate of investment expenditure.

Symbolically, Let $\mathrm{K}=$ Capital Stock, = Level of output, $=\mathrm{K} / \mathrm{Y}-$ Capacity output ratios, = accelerator, $\mathrm{f} \mathrm{W}$ $=\mathrm{K} / \mathrm{Y},=\mathrm{WY}, \mathrm{K}=\mathrm{W} \Delta \mathrm{Y}$ This is the accelerator principle. As output change $(\Delta \mathrm{k})$ changes the same direction, et $\mathrm{K}_{\mathrm{t}}$ $=$ capital stock of period $\mathrm{t}_{\mathrm{t}}=$ output level at period $\mathrm{t}$.

$\mathrm{K}_{\mathrm{t}}=$ capital stock at the previous period, ${ }_{\mathrm{t}}-{ }_{\mathrm{I}}=$ output level at previous period. $\mathrm{W}=\Delta \mathrm{K} / \Delta \mathrm{Y}$ Accelerator. 
J.W Clark made use of potential output in his analysis. The flexible accelerator theory removes one of the major. Weakness of the simple accelerator principle that the capital stock is optimally adjusted any time lag. In the flexible accelerator principle, there are lags in the adjustment process between the level of output and the level of capital stock. This is also known as the capital adjustment model

\section{Model Specification}

\section{Methodology}

Following the various theories especially the Rowstow theory and Bahtia (1960) study where investment was expressed as a function of inflationary rate. A model showing the relationship between inflation and investment is specified thus

$\mathrm{INV}=\mathrm{F}\left(\right.$ Infl, Int, RGDP, Ms, D/Y, Infl $_{\mathrm{t}-\mathrm{I}}$ i.e Rinv $=\beta_{0}+\beta_{1} \operatorname{Infl}_{t}+\beta_{2} \operatorname{Int}_{t}+\beta_{3} \operatorname{RGDP}_{t}+\beta_{4} \mathrm{Ms}_{t}+\beta_{5} \mathrm{D} / \mathrm{Y}_{\mathrm{t}}+\beta_{6} \mathrm{INFl}_{\mathrm{t}-1}+\mathrm{U}_{\mathrm{t}} \ldots \ldots \ldots$... (2)

Where $;$ Rinv $=$ Real Investment (Proxy by Real capital formation), INFL = Inflation rate, int $=$ Interest rate, $\mathrm{RGDP}=$ real income, $\mathrm{Ms}=$ money stock, $\mathrm{D} / \mathrm{Y}=$ debt income ratio (proxy debt) overhang), $\mathrm{NFL}_{\mathrm{t}-1}=$ lagged inflationary rate

A priori Expectation: $\beta_{1}>0 ; \beta_{2} ; \beta_{0}>0 \beta_{4}>0 ; \beta_{5}<0 ; \beta>0$

Method of Data Analysis

To be able to establish a dynamic relationship between investment and inflationary dynamics in Nigeria, co-integration and error correction model estimating technique is adopted using Johansen procedure. The co-integration will be preceded by the unit-root test using the argument dicker fuller (ADF) test. This will be also used for the residual stationary test before the error correction Model (ECM).

\section{Estimating Technique}

The first step is to examine whether the time series contained in the equation has a unit root. In the cointegration literature, the more frequently used tests for a unit root are the Augmented Dickey-Fuller (1979 and 1981) Philips - Perron (1988) and Perron (1986 and 1988) test. These tests agreed in their treatment to the intercept parameter. Thus, the null hypothesis model to test for unit root has the following form:

$$
X_{t}=\mu+a X_{t-1}+E_{t}
$$

And the model under the alternative hypothesis:

The estimating technique adopted for this study is cointegration and error connection model. According to Engle and Granger methodology,

$$
X_{t}=\mu+\theta\left(t-\frac{T}{2}\right)+a X_{t-1}+E_{t}
$$

When $X_{t}$ is the of the time series, and under the null hypothesis; $a=1$ and $\theta=0$. T represents the number of observations. In this paper, we use the Augmented Dickey-Fuller $(A D F)$ to test for the stationarity of the time series. The $A D F$ test can be obtained by applying $O L S$ to estimate the coefficients of the following relation:

$$
\Delta X_{t}=\mu+\theta_{t}+X_{t-1}+\sum_{1}^{n} \lambda_{i} \Delta X_{t-1}+u_{i}
$$

$\mathrm{n}$ is chosen to eliminate the autocorrelation. If a unit root exists, then $y=a-1$ would not be statistically different from zero. The $A D F$ test can be conducted by comparing the t-value on the coefficient of $X_{t-1}$ with critical values.

The Granger representation indicates that if $X_{t}$ and $\lambda_{t}$ are integrated; they will have an error correlation representation as follow:

$a(L) \Delta \gamma_{i}=a_{0}-\lambda\left(y_{t}-a_{i} X_{t}\right)+b(L) \Delta \lambda_{t}+c(L) E_{t}$

Where $a(L), b(L)$ and $c(L)$ are stable and inveritible polynomials, respectively. Such models provide a more attractive way of presenting and modeling cointegrating series. The error correction models combine the long run $\left(y_{t}-a X_{t}\right)$ and the short run dynamics.

The second step of Engle and Granger methodology consist to estimate the following regression:

$\Delta y_{t}=a+\sum a^{\tau} \Delta y_{t-1}^{\tau} \sum \beta_{j} \Delta X_{t-1}+b E C_{t-1}$

Where A denotes the first difference and the EC represents the error term. The estimated error term coefficient must have statistically significant negative sign. This coefficient indicates the percentage of the disequilibrium 
in the dependent variable that would be adjusted from period to another. It is widely recognizable that Engle and Granger test for cointegration would be enough if we want to examine the effect of error correction mechanism on the dependent variable for two sequences periods such as $t$ and $t-1$.

The maximum Likelihood procedure (Johansen's test), suggested by Johansen (1988 and 1991) is particularly preferable when the number of variables in the study exceeds two variables due to the possibility of existence of multiple cointegrating vectors. The advantage of Johansen's test is not only limited to multivariate case, but it is also preferable than Engle-Granger approach even with a two-variable-model (Gonzalo, 1990).

To determine the number of cointegrating vectors, (Johansen, 1988 and 1991) and Johansen and Juselius (1990) suggested two statistic tests. The first one is the trace test $\left(\lambda_{\text {trace }}\right)$. It tests the null hypothesis, that the number of distinct cointegrating vectors is less than or equal to $(\mathrm{q})$ against a general unrestricted alternative $(\mathrm{q}=\mathrm{r})$. The second statistical test is the maximal eigenvalue test $\left(\lambda_{\max }\right)$. This test concerns a test of the null hypothesis that there is $(r)$ of cointegrating vectors against the alternative that there is $(r+1)$ cointegrating vectors.

Source of Data

Data on all the variables used in the empirical analysis were all sourced from the CBN statistical Bulletin 2006 edition.

\section{Results And Discussion}

This section begins by examine the time series properly of the variables used in the model. This was done through the test for stationarity.

Table 1. UNIT ROOT TEST RESULT

\begin{tabular}{|l|l|l|}
\hline Variable & ADF Statistic & Order of Integration \\
\hline RINV & -4.07828 & $\mathrm{I}(1)$ \\
\hline RGDP & -3.407437 & $\mathrm{I}(1)$ \\
\hline INFL & -3.762270 & $\mathrm{I}(0)$ \\
\hline INT & -5.911353 & $\mathrm{I}(1)$ \\
\hline MS & 3.1711067 & $\mathrm{I}(0)$ \\
\hline INFL(-1) & -3.294386 & $\mathrm{I}(0)$ \\
\hline DEBT & 4.987241 & $\mathrm{I}(2)$ \\
\hline
\end{tabular}

Note: ADF critical value at $5 \%$ is -2.9527

Source: author's computation

The ADF test in this study shows that only MS and INFL (-1) are stationary at the level while RINV, RGDP and INT are only stationary at the first difference while debt could not be found to stationary at both levels but only stationary of the second difference. It could therefore be argued that equilibrium does not exist in the short run and therefore the need to know whether equilibrium exist in the long run. As a result of this, the test for cointegration was performed using the Johansen $(1991,1995)$ maximum likelihood estimation approach.

TABLE 2: CO-INTEGRATION TEST

\begin{tabular}{|l|l|l|l|l|}
\hline Engel Value & Likelihood Radio & Critical Values 5\% & Critical Value 1\% & $\begin{array}{l}\text { Hypothesized No of CE } \\
(5)\end{array}$ \\
\hline 0.890762 & 207.0283 & 94.15 & 103.18 & None** \\
\hline 0.813721 & 133.9590 & 68.52 & 76.07 & At most $1 * *$ \\
\hline 0.787627 & 78.50208 & 47.21 & 54.46 & At most 2** \\
\hline 0.35874 & 27.37150 & 29.68 & 35.65 & At most 3 \\
\hline 0.202389 & 12.69687 & 15.41 & 20.04 & At most 4 \\
\hline 0.146679 & 5.234434 & 3.76 & 6.65 & At most 5 \\
\hline
\end{tabular}

$*(* *)$ denoted rejection of the hypothesis at $5 \%(1 \%)$ significance level

L.R. Test indicates 3 co-integration equation(s) at 5\% significance level

Source: author's computation

Table 2 showed that there are three (3) co-integrating vector in the investment function. This means that there is a long term equilibrium relationship between the investment and variable captured in the model. To be able to correct for the error between the short run and long period the error correction mechanism was used. But before then the co-integration regression result is as follows: 
Table 3

\begin{tabular}{|l|l|l|}
\hline Repressors & Coefficients & T-Ratio \\
\hline C & -55.18527 & -1.391 \\
\hline RGDP & 0.779370 & 1.537 \\
\hline INFL & -0.297201 & -0.964 \\
\hline INT & 0.394974 & 0.450 \\
\hline MS & 0.175198 & 2.514 \\
\hline INFL(-1) & 0.386202 & 1.250 \\
\hline Debt. D/Y & 0.142139 & 1.989 \\
\hline
\end{tabular}

$\mathrm{R}^{2}=0.97$

F-sat $=155.04$

$\mathrm{D}: \mathrm{w}=1.76$

RINV = -55.19 -0.29infl + 0.78RGDP + 0.18MS + 0.39INT + 0.39infl(-1) + 0.142139 D/Y

Source: Author' Computation

From table 3, result shows that there is a positive relationship between and real income (RGDP) and real investment in Nigeria. That is a unit increase in real income in Nigeria should lead to about $77.9 \%$ increase in the level of investment in the economy.

There is an inverse relationship between rate and investment. This is in line with the Apriori expectation. Form the result a percent increase in inflation will lead to a reduction in investment to the tune of $29.7 \%$. the implication of this is that government must make sure that inflation rate in the country must be totally curtailed.

One surprising result from the study is its positive relationship between interest rate and investment. The reason for this type of relationship might not be unconnected with what Anyawu (1995) called the existence of many risk takers who are investor in the Nigerian economy this set of investors might not be concerned with interest rate on loan but profit and duration of realizing such profits. The money supply and debt are both positively related to investment. Meaning that a percentage change in money supply and also in debt will bring about change in investment to the turn of $17.5 \%$ and $14 \%$ respectively. But the carry-over effect of the inflationary rate from the previous year exhibited a direct relationship. The effect of this might have been soaked by economic activities in the previous period before reaching the current period.

The value of the $\mathrm{R}^{2}$ is 0.97 indicating that the explanatory variable explains about $97 \%$ of the systemic variation in the investment. Despite the inverse relationship between inflation and investment, the value of the T. ratio showed that inflationary rate alone does not have significant impact on the level of investment in Nigeria. Likewise other variables in the model except the real income i.e. RGDP. The F statistic shows that the overall regression is statistically significant.

However the result reveals that there is no problem of autocorrelation as the Durbin-Watson is 1.76

Table 4

\section{Error Correction Parsimonious Model}

\begin{tabular}{|l|l|l|}
\hline Explanatory & Elasticities & t. Value \\
\hline Constant & 0.230794 & 1.338402 \\
\hline$\Delta$ LOG (RGDP) & 1.916858 & 1.345313 \\
\hline$\Delta$ LOG (INFL) & -0.206753 & -1.796365 \\
\hline$\Delta$ LOG (INT) & 0.004743 & 0.014460 \\
\hline$\Delta$ LOG (Ms) & 0.716511 & 0.909980 \\
\hline$\Delta$ LOG (INFL(-1)) & -0.018658 & -0.175082 \\
\hline$\triangle$ LOG (DEBT) & 0.080215 & 0.149997 \\
\hline$\triangle$ ECM (-1) & -0.007718 & -0.019870 \\
\hline
\end{tabular}
$\mathrm{R}^{2}=0.9634$
F-Sat $=137.01$
$\mathrm{D}: \mathrm{w}=1.68$

Source: Author's Computation

The result in table 5 analyses the short run dynamics among the variables. This is further evident in the value of the ECM which is correctly signed i.e. negative. This means that the ECM is able to correct any deviation from the long run equilibrium relationship between investment and its past values of inflationary rate.

\section{Conclusion and Recommendation}

Some conclusion can be drawn from the findings in this study. Firstly, the study has revealed that inflationary rate does not have positive impact on the level of investment in Nigeria. Again the empirical findings have shown that increase in GDP will positively influence the level of investment. The policy recommendation is that Nigeria government should puruse vigorously, policy that will dreastically reduce the current high rate of inflation in the country while trying to boost domestic production so as to increase the GDP. Generally, this study has therefore, shown that low inflation and growing real income are central to massive 
capital formulation. It is therefore important that policies that will create conditions for this to happen should be of great concern to policy makers.

\section{References}

[1] Anyawu, J.C. and Oaikhenan, H.E (1995) "The Modern Macro Economic Theory and Application in Nigeria" Jonnane Educational Publishers Limited, Onisha, Pp. 159 -185

[2] Arunwarlds W.C. (1951) "Depreciation as cause of inflation in African Countries: an Empirical Analysis".

[3] Bhatia R.J. (1960). "Inflation, Deflation and Economic Development IMF Staff Papers

[4] Clarke J.N (1936) Acceleration Principles and its Application. American Economic Review.

[5] Durnace, J. (1975) "The Impact of exchange rate uncertainty on the level of investment" economic Journal 109, C55-C67

[6] Eckstein. C (1958), "Foced Investment Decisions in UK manufacturing: the importance of Tobins Q Output and Debt", European Economic Review, 39, 919-941.

[7] Friedman M. (1958), "What price Guild Posts" in Shuttz G. and Alber RZ (Eds) guidelines, informal controls and the market place, University of Chicago Press, Chicago, 17-39

[8] Iyoha, M.A (1975) "Inflation and Openness" In less Development Economics, A cross Country Analysis" Economic Development and Cultural Change Vol. 22, No. 1, October 1973.

[9] Odoko F. O (2003). Contemporary Economic Policy Issues CBN Publication.

[10] Osakwe et al (1982), Nigeria and the IMF, Heinmann Books Nigeria. Ibadan

[11] Rowstow, R.E (1934), "Conflict, Inflation and Money" Cambridge Formal of Economics, 1, 215 -239

[12] Schwartz, G. R. (1973), A world of Inflation, (New York Barnes and Noble)

[13] Thirwall A.P. (1974) Inflation, Saving and Growth in Developing Economics Macmillan, London. 